Research Article

\title{
Identification and Quality Evaluation of Raw and Processed Asarum Species Using Microscopy, DNA Barcoding, and Gas Chromatography-Mass Spectrometry
}

\author{
Guangzhe Yao, ${ }^{1,2}$ Wenjuan $M a,{ }^{2}$ Xuhua Huang, ${ }^{2}$ Qi Jia, ${ }^{2}$ Jiayuan Shen, ${ }^{2}$ Yanxu Chang $\mathbb{D}^{2}$ \\ Huizi Ouyang $\mathbb{D}^{1,2}$ and Jun $\mathrm{He} \mathbb{1}^{2}$ \\ ${ }^{1}$ First Teaching Hospital of Tianjin University of Traditional Chinese Medicine, Tianjin 300193, China \\ ${ }^{2}$ Tianjin State Key Laboratory of Modern Chinese Medicine, Tianjin University of Traditional Chinese Medicine, \\ Tianjin.301617, China
}

Correspondence should be addressed to Huizi Ouyang; huihui851025@163.com and Jun He; hejun673@163.com

Received 5 February 2020; Revised 18 March 2020; Accepted 24 March 2020; Published 13 April 2020

Academic Editor: Boryana M. Nikolova-Damyanova

Copyright (C) 2020 Guangzhe Yao et al. This is an open access article distributed under the Creative Commons Attribution License, which permits unrestricted use, distribution, and reproduction in any medium, provided the original work is properly cited.

Asarum (Aristolochiaceae) is one of the common herbs used to relieve exterior syndromes. Some volatile components of Asarum which have toxic effect may cause adverse reactions such as headache, general tension, unconsciousness, and respiratory paralysis. Therefore, Asarum is normally processed to reduce such toxicity and adverse effects. The bioactive ingredients contained in different Asarum herbs vary significantly; this variation may be attributed to their differences in species, origins, or processing methods. In this study, 16 batches of Asarum herbs were collected, and their species were identified using DNA barcoding, which is a method for distinguishing plant species, coupled with microscopy. A gas chromatography-mass spectrometry (GC-MS) method for simultaneous determination of 10 compounds was established to evaluate the contents of raw and processed Asarum herbs. Multivariate analysis was then applied to compare different batches of herbs based on the GC-MS data. DNA barcoding identified the herbs as being derived from four sources, and herbs from different origins showed different microscopic features. The results demonstrated that most of the samples were clearly clustered into distinct groups that corresponded to species types. All raw and processed samples were classified by partial least squares discriminant analysis (PLS-DA) based on the 10 analyzed compounds. The findings suggested that safrole and methyleugenol with a variable importance in the project (VIP) $>1$ are unique compounds that can be used to differentiate between Asarum species. Safrole, methyleugenol, and 2,6,6-trimethylcyclohepta-2,4dien-1-one were identified as significant constituents, the presence of which can be used to differentiate between raw and processed Asarum samples. These results indicate that species and processing methods show important effects on the composition of Asarum herbs.

\section{Introduction}

According to the Chinese Pharmacopoeia (2015 edition), Asarum herbs originated from the dry roots and rhizomes of plants in the family Aristolochiaceae, which includes Asarum heterotropoides Fr. Schmidt var. mandshuricum (Maxim.) Kitag., Asarum sieboldii Miq. var. seoulense Nakai, and Asarum sieboldii Miq [1]. Asarum maximum Hemsl. is used as a succedaneum in some regions of China for the treatment of various diseases [2]. The use of the herb was first reported in the monograph Shennong Compendium of
Materia Medica (Shennong Bencaojing) compiled during the Eastern Han dynasty (25-220 AD) [3]. In general, methyleugenol, safrole, and other volatile components (estragole, cineole, and $\alpha$-terpineol, among others) are considered to be the major bioactive components of Asarum herbs [4]. Studies have shown that Asarum shows antiseptic properties and can also be used to treat cough, dyspnea, headache, rheumatic arthralgia, sinusitis, and toothache [1,5-7].

The quality of medicinal plants is dependent on genetic and environmental factors; even plants of the same species can have a different chemical composition and function if 
they are of different geographical origin [8]. Asarum is cultivated in various regions of China including Liaoning, Shanxi, and Jilin, which makes the identification of this herb using traditional methods challenging [9]. Characteristic based, microscopic identification, and physicochemical identification are common methods used to identify the constituents of traditional Chinese medicines (TCMs) $[10,11]$. However, it is difficult to characterize medicinal materials from multiple sources, especially when the medicines are in the form of a powder. DNA barcoding, a simple operating system, can enable the accurate and rapid identification of raw plants, cells, tissues, decoction products, and powdered medicinal materials and has the benefits of good accuracy and high repeatability [12-16].

In TCM theory, processing (plain-frying or stir-frying until brown, steaming, braising, or stir-frying with wine) is necessary to promote the therapeutic effects and/or reduce the side effects of herbs by decreasing their levels of toxic constituents [17-19]. Chemical reactions may occur during the processing of TCMs, such as hydrolysis reaction, oxidation reaction, displacement reaction, isomerization reaction, and decomposition reaction. For example, after processing Pinellia ternata with ginger water, the gingerols in the ginger exert antagonistic effects on the stimulatory toxicity of the Pinellia toxic needle crystal [20]. Research has indicated that the compositions of raw and processed Asarum herbs are distinct from each other [21]. The combination of mass spectrometry and PLS-DA can provide a comprehensive and multivariate description of the chemical composition of herbal medicines. However, few studies have reported these methods in the multicomponent analysis of Asarum or in the comparison of the chemical components that differ between the raw and processed herbs. Therefore, a reliable and comprehensive analytical method is needed to determine several components simultaneously, thus enabling the evaluation of quality in raw and processed samples of Asarum.

In our study, microscopic techniques and DNA barcoding were applied to identify the features of and species contained in 16 batches of Asarum herbs. Ten volatile components, namely, (1R)-(+)-alpha-pinene, (-)- $\beta$-pinene, (+)-car-3-ene, cineole, (-)-borneol, safrole, estragole, $\alpha$-terpineol, methyleugenol, and 2,6,6-trimethylcyclohepta2,4-dien-1-one, were simultaneously evaluated using gas chromatography-mass spectrometry (GC-MS), and the components of raw and processed Asarum collected from different areas were analyzed by PLS-DA. This study provides a new point of view on the genetic basis and classification of Asarum. Meanwhile, it highlights the influence of processing on the content of volatile components and this information will be useful in the evaluation and differentiation of raw and processed Asarum herbs.

\section{Materials and Methods}

2.1. Chemicals. Reference standards of (1R)-(+)-alpha-pinene, (+)-car-3-ene, cineole, (-)- $\beta$-pinene, (-)-borneol, 2,6,6-trimethylcyclohepta-2,4-dien-1-one, $\alpha$-terpineol, estragole, safrole, and methyleugenol were purchased from
Desite Biotech Co., Ltd. N-Hexane was provided by Kangkede Technology Co., Ltd. Glycerol was obtained from Tianjin Fengchuan Chemical Reagent Co., Ltd. Chloral hydrate was purchased from Tianjin Kemiou Chemical Reagent Co., Ltd. The plant genomic DNA kit was provided by Tiangen Biotech (Beijing) Co., Ltd. Deionized water was prepared using a Milli-Q water purification system.

2.2. Plant Material. Asarum herbs from 16 areas were collected from different provinces of China and identified by professor Jun He of the Tianjin State Key Laboratory of Modern Chinese Medicine. Asarum was deposited in the TCM library, Tianjin University of Traditional Chinese Medicine, Tianjin, China. The origins of the samples are shown in Table 1.

2.3. Microscopic Identification of Asarum. The species of Asarum were identified according to the root appearance and microscopic features. After screening with a no. 4 sieve, each dried sample was ground into a powder using an electric grinder. Samples were placed on slides and permeated twice with 1-3 drops of chloral hydrate and then sealed with diluted glycerol and a coverslip. Images of Asarum powder samples observed with a light microscope under $10 \mathrm{x}$ magnification were taken with a digital camera.

2.4. DNA Barcoding Analyses. Approximately, $30 \mathrm{mg}$ of dried powder from each sample (roots and rhizomes) was accurately weighed and frozen with liquid nitrogen before undergoing further grinding. The total genomic DNA was isolated from the material using the Plant Genomic DNA Kit DP305 (TIANGEN), according to the manufacturer's instructions, and stored at $-20^{\circ} \mathrm{C}$.

The primers used to amplify DNA at the ITS2 region were $5^{\prime}$-AGAAGTCGTAACAAGGTTTCCGTAGG-3' (forward) and $5^{\prime}$-TCCTCCTCCGCTTATTGATATGC-3' (reverse) [22, 23]. PCR amplification was performed in a $25-$ $\mu \mathrm{L}$ reaction tube with $2 \mu \mathrm{L}$ DNA template $(10 \mu \mathrm{M}), 12.5 \mu \mathrm{L}$ $2 \times$ Gflex PCR buffer (Takara), $0.5 \mu \mathrm{L}$ of each primer, $0.5 \mu \mathrm{L}$ Tks Gflex DNA polymerase (1.25 units/ $\mu \mathrm{L}$, Takara), and

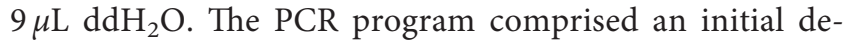
naturation step at $98^{\circ} \mathrm{C}$ for $1 \mathrm{~min}$, followed by 40 cycles of denaturation at $98^{\circ} \mathrm{C}$ for $10 \mathrm{~s}$, annealing at $56.5^{\circ} \mathrm{C}$ for $15 \mathrm{~s}$, and elongation at $68^{\circ} \mathrm{C}$ for $30 \mathrm{~s}$, with a final extension step at $68^{\circ} \mathrm{C}$ for $5 \mathrm{~min}$. The amplified products were detected on $2 \%$ agarose gels.

The PCR products were sequenced based on Sanger sequencing technology by the sequencing company (Gitech Solutions Co., Limited). The obtained sequences were searched against the GenBank database using BLAST to determine the species of each sample [24, 25].

\subsection{Quantification Using GC-MS}

2.5.1. Processing Methods of Asarum. The raw Asarum samples were cut into segments and stir-fried in a metallic 
Table 1: Detailed information of Asarum from 16 regions.

\begin{tabular}{|c|c|c|c|c|}
\hline Batch & Origin & $\begin{array}{c}\text { Lot } \\
\text { number }\end{array}$ & Appearance features & Power characteristics \\
\hline 1 & Jingyu & 20180817 & Roots long, multibranch & $\begin{array}{l}\text { The surface cells rectangular and slightly wavy, scalariform vessel, oil cells } \\
\text { relatively incompact, small number of stone cells, more starches }\end{array}$ \\
\hline 2 & Yanbian & 20180820 & Roots long, multibranch & $\begin{array}{l}\text { The surface cells rectangular and slightly wavy, scalariform vessel, oil cells } \\
\text { relatively incompact, small number of stone cells, more starches }\end{array}$ \\
\hline 3 & Fushun & 20180817 & Roots long, multibranch & $\begin{array}{l}\text { The surface cells rectangular and slightly wavy, scalariform vessel, oil cells } \\
\text { relatively incompact, small number of stone cells, more starches }\end{array}$ \\
\hline 4 & Zhaotong & 20180915 & Roots long, multibranch & $\begin{array}{l}\text { The surface cells rectangular and slightly wavy, scalariform vessel, oil cells } \\
\text { relatively incompact, small number of stone cells, more starches }\end{array}$ \\
\hline 5 & Guilin & 20180807 & $\begin{array}{l}\text { Roots relatively long and } \\
\text { thick, }\end{array}$ & More starches and wood fiber, stone cells none. \\
\hline 6 & Shennongjia & 20180620 & Roots long, multibranch & $\begin{array}{l}\text { The surface cells rectangular, scalariform vessel, a small number of stone } \\
\text { cells, and more starches. }\end{array}$ \\
\hline 7 & Xinbin & 20180802 & Roots long, multibranch & The surface cells rectangular, scalariform vessel, and more starches. \\
\hline 8 & Tiexi & 20180904 & Roots long, multibranch & $\begin{array}{l}\text { The surface cells rectangular and slightly wavy, scalariform vessel, oil cells } \\
\text { relatively incompact, small number of stone cells, more starches }\end{array}$ \\
\hline 9 & Dingxi & 20181016 & $\begin{array}{l}\text { Roots relatively long and } \\
\text { thick }\end{array}$ & More starches and wood fiber, stone cells none. \\
\hline 10 & Changzhi & 20180306 & $\begin{array}{l}\text { Roots long and thin } \\
\text { multibranch }\end{array}$ & $\begin{array}{l}\text { The surface cells rectangular and slightly wavy, scalariform vessel, oil cells } \\
\text { relatively incompact, small number of stone cells, more starches }\end{array}$ \\
\hline 11 & Bijie & 20180818 & $\begin{array}{l}\text { Roots relatively long and } \\
\text { thick, less branch }\end{array}$ & More starches and wood fiber, stone cells none. \\
\hline 12 & Benxi & 20180818 & $\begin{array}{l}\text { Roots long and thin, more } \\
\text { fibrous roots }\end{array}$ & The surface cells rectangular, scalariform vessel, and more starches. \\
\hline 13 & Panjin & 20180811 & Roots long, multibranch & $\begin{array}{l}\text { The surface cells rectangular, scalariform vessel, a small number of stone } \\
\text { cells, and more starches. }\end{array}$ \\
\hline 14 & Chifeng & 20181011 & $\begin{array}{l}\text { Roots long and thin, } \\
\text { multibranch }\end{array}$ & $\begin{array}{l}\text { The surface cells rectangular and slightly wavy, scalariform vessel, oil cells } \\
\text { relatively incompact, small number of stone cells, more starches }\end{array}$ \\
\hline 15 & Qinling & 20180726 & $\begin{array}{l}\text { Roots long and thin, } \\
\text { multibranch }\end{array}$ & $\begin{array}{c}\text { The surface cells rectangular and slightly wavy, scalariform vessel, oil cells } \\
\text { relatively incompact, more starches }\end{array}$ \\
\hline 16 & Yulin & 20180721 & $\begin{array}{l}\text { Roots long and thin, } \\
\text { multibranch }\end{array}$ & $\begin{array}{c}\text { The surface cells rectangular and slightly wavy, scalariform vessel, oil cells } \\
\text { relatively incompact, more starches }\end{array}$ \\
\hline
\end{tabular}

pan at $120-140^{\circ} \mathrm{C}$ over a medium flame, for about $15 \mathrm{~min}$ or until the exterior of the sample turns brown colour, with scorched spots.

2.5.2. Preparation of Samples. Asarum samples (roots and rhizomes) were dried and grounded into powder. The powder of raw and processed Asarum samples was accurately weighed $(50.0 \mathrm{~g})$ and subjected to hydrodistillation for $6 \mathrm{~h}$ at 100 volt by an essential oil extractor. The essential oil was collected after cooling to room temperature. The essential oil obtained was stored in refrigeration at $4^{\circ} \mathrm{C}$. A $5 \mu \mathrm{L}$ sample of volatile oil (raw or processed) was accurately measured and dissolved in $50 \mathrm{~mL}$ of $\mathrm{N}$-hexane.

Ten reference standards: (1R)-(+)-alpha-pinene, $(+)$-car3 -ene, cineole, $\alpha$-terpineol, (-)- $\beta$-pinene, (-)-borneol, 2,6,6trimethylcyclohepta-2,4-dien-1-one, estragole, safrole, and methyleugenol were dissolved in $\mathrm{N}$-hexane at a final concentration of $1 \mathrm{mg} / \mathrm{mL}$ as stock solutions, respectively. Working standard solutions were further obtained by diluting the above stock solutions in appropriate amounts.

2.5.3. Gas Chromatographic and Mass Spectrometry Conditions. Automated analysis was performed on a Shimadzu GC-MS QP-2010 Ultrasystem equipped with an AOC-20i autosampler. Chromatographic separations were conducted on a DB-17 capillary column $(30 \mathrm{~m} \times 0.25 \mathrm{~mm} \times 0.25 \mu \mathrm{m}$ film thickness). The column temperature was programmed as follows: $3 \mathrm{~min}$ at $40^{\circ} \mathrm{C}, 6^{\circ} \mathrm{C} / \mathrm{min}$ to $106^{\circ} \mathrm{C}, 3^{\circ} \mathrm{C} / \mathrm{min}$ to $142.6^{\circ} \mathrm{C}$, $142.6^{\circ} \mathrm{C}$ for $1 \mathrm{~min}, 6^{\circ} \mathrm{C} / \mathrm{min}$ to $180^{\circ} \mathrm{C}$, and finally $4^{\circ} \mathrm{C} / \mathrm{min}$ to $200^{\circ} \mathrm{C}$. High-purity helium was used as the carrier gas at a flow rate of $1.3 \mathrm{~mL} / \mathrm{min}$. Split injection was set at a split ratio of $50: 1$, and the injection temperature was $250^{\circ} \mathrm{C}$.

The optimized conditions for the MS detector were as follows: ionization source temperature, $230^{\circ} \mathrm{C}$; ionization energy, $70 \mathrm{eV}$; interface temperature, $250^{\circ} \mathrm{C}$; full scan range, $m / z$ 30-600; and scan rate, $0.30 \mathrm{~s}$ per scan. The MS data were acquired in the electron-impact mode. Compounds were identified by the standard substance and NIST08 Mass Spectral Library. Components were quantified by the external standard curve method $[7,26]$.

2.5.4. GC-MS Method Validation. The linearity of the assay for the test compounds was assessed by least square linear regression of the analyte-to-standard peak area ratio $(y)$ versus the normalized standard concentration $(x)$. Lower limit of quantification (LLOQ) for each sample was defined based on the concentrations that generated peaks with signal-to-noise values $(S / N)$ of 10 . For precision, the 


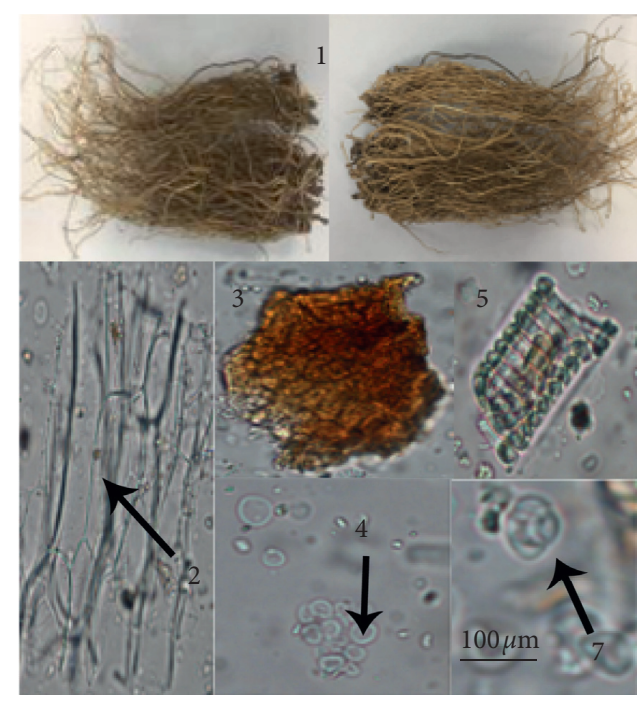

(a)

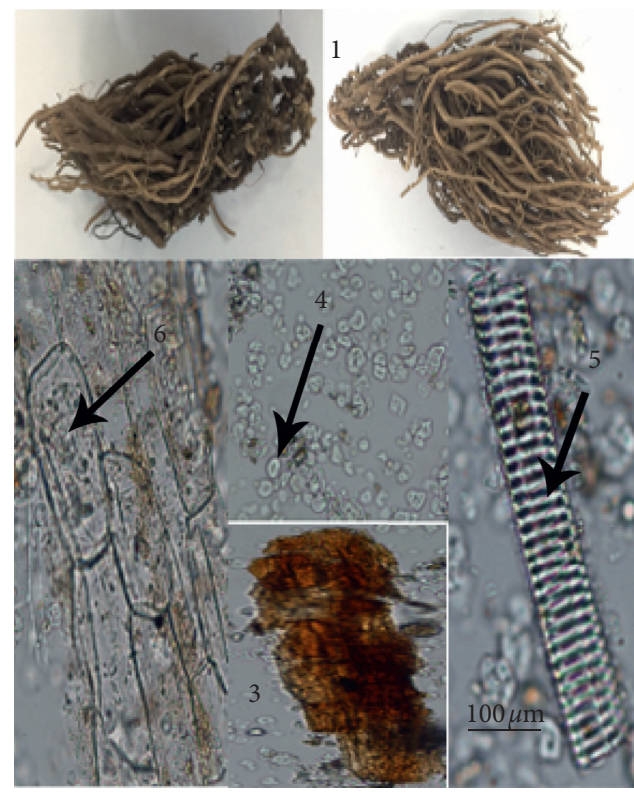

(c)

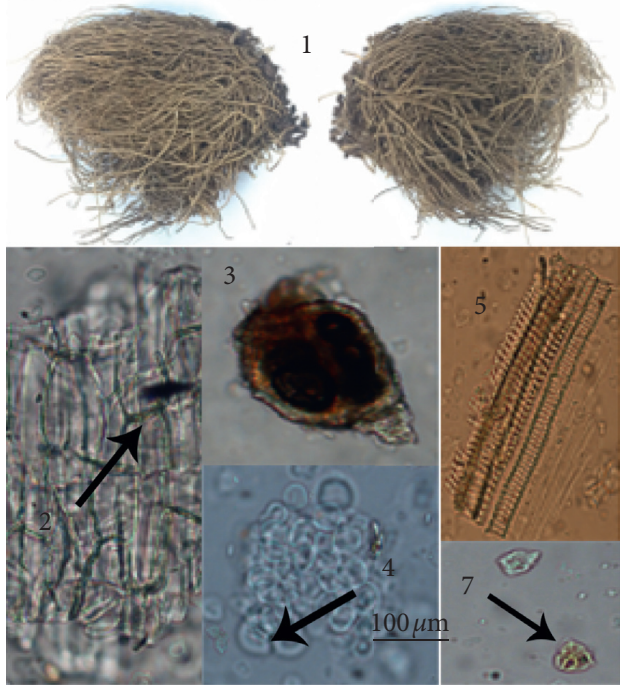

(b)

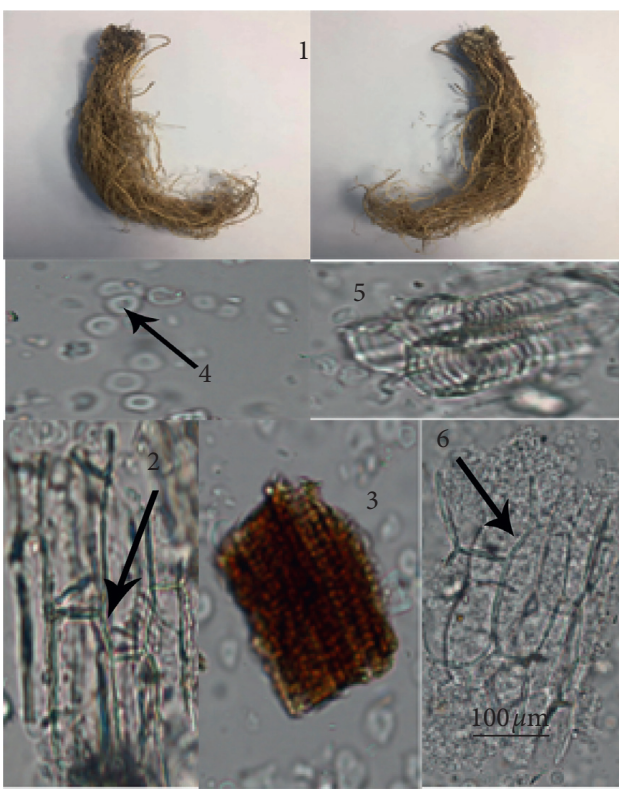

(d)

Figure 1: The appearance and microscopic features of Asarum samples: (a) Asarum heterotropoides Fr. Schmidt var. mandshuricum (Maxim.) Kitag.; (b) Asarum sieboldii Miq.; (c) Asarum maximum Hemsl.; (d) Asarum sieboldii Miq. var. seoulense Nakai. (1) root; (2) root surface cells; (3) oil cells; (4) starch grain; (5) vessel; (6) secretory cell; and (7) stone cell.

method was evaluated by intraday and interday variability. RSDs were calculated as the measure of precision. In the repeatability examination, six replicates of the samples from the same batch were extracted and analyzed. To evaluate the stability of the analytes, sample solutions were stored at room temperature and then analyzed by replicate injections at $0,2,4,8,12$, and $24 \mathrm{~h}$. RSDs were used to assess stability. The recovery was evaluated by adding known amounts of 10 standard solutions to samples, and these were used to further investigate the accuracy of the method. Recovery was calculated using the following formula: recovery $(\%)=($ amount found - original amount $) /$ amount spiked $\times 100 \%$.
2.6. Statistical Analysis. Differences between the Asarum samples were analyzed by PLS-DA. This method establishes the regression relationship between the matrixes, so as to get a better regression prediction result. When a supervised pattern recognition method is employed, the sample data are divided into training and validation sets. The classification model is obtained using the training set, while the accuracy of the prediction is verified using the validation set. In this research, the GC-MS method was applied to analyze the Asarum samples including batches of raw and processed Asarum samples. A total of 10 volatile compounds were used to evaluate the differences in the above samples. Statistical analyses were carried out using SIMCA-P 14.1 software. The 
TABLE 2: The molecular identification result information.

\begin{tabular}{lcccc}
\hline Batch & Origin & Length (bp) & DNA identification & Reference accession number \\
\hline 1 & Jingyu & 221 & Asarum heterotropoides Fr. Schmidt var. mandshuricum (maxim.) Kitag. & KX674960.1 \\
2 & Yanbian & 221 & Asarum heterotropoides Fr. Schmidt var. mandshuricum (maxim.) Kitag. & KX674960.1 \\
3 & Fushun & 221 & Asarum heterotropoides Fr. Schmidt var. mandshuricum (maxim.) Kitag. & KX674960.1 \\
4 & Zhaotong & 221 & Asarum heterotropoides Fr. Schmidt var. mandshuricum (maxim.) Kitag. & KX674960.1 \\
5 & Guilin & 221 & Asarum maximum Hemsl. & FJ980374.1 \\
6 & Shennongjia & 221 & Asarum sieboldii Miq. & MF096022.1 \\
7 & Xinbin & 221 & Asarum sieboldii Miq. Var. seoulense Nakai & AB2477109.1 \\
8 & Tiexi & 221 & Asarum heterotropoides Fr. Schmidt var. mandshuricum (maxim.) Kitag. & KX674960.1 \\
9 & Dingxi & 221 & Asarum maximum Hemsl. & FJ980374.1 \\
10 & Changzhi & 221 & Asarum heterotropoides Fr. Schmidt var. mandshuricum (maxim.) Kitag. & KX674960.1 \\
11 & Bijie & 221 & Asarum maximum Hemsl. & FJ980374.1 \\
12 & Benxi & 221 & Asarum sieboldii Miq. Var. seoulense Nakai & AB247109.1 \\
13 & Panjin & 221 & Asarum sieboldii Miq. & MF096022.1 \\
14 & Chifeng & 221 & Asarum heterotropoides Fr. Schmidt var. mandshuricum (maxim.) Kitag. & KX674960.1 \\
15 & Qinling & 221 & Asarum heterotropoides Fr. Schmidt var. mandshuricum (maxim.) Kitag. & KX674960.1 \\
16 & Yulin & 221 & Asarum heterotropoides Fr. Schmidt var. mandshuricum (maxim.) Kitag. & KX674960.1 \\
\hline
\end{tabular}

statistical fitness of the model was evaluated by $R^{2} X, R^{2} Y$, and $Q^{2}$.

\section{Results and Discussion}

Distinct microscopic features were observed in the upper epidermis, oil cells, starch granules, vessels, and secretory cells. The microscopic appearance and features of Asarum are shown in Figure 1. Asarum heterotropoides Fr. Schmidt var. mandshuricum (Maxim.) Kitag. roots are slender, the surface cells are rectangular and slightly wavy, and they have scalariform vessels and relatively incompact oil cells, with a small number of stone cells and an abundance of starch granules. Asarum sieboldii Miq. has long roots, the surface cells are rectangular, and it has scalariform vessels, a small number of stone cells, and an abundance of starch granules. Asarum sieboldii Miq. var. seoulense Nakai has long, fibrous roots and an abundance of starch granules. Asarum maximum Hemsl. has horizontal rhizomes, and it has an abundance of starch granules, but, in our observations, no stone cells. The result demonstrated that the presence or absence of stone cells can be used as a distinguishing feature to differentiate Asarum heterotropoides Fr. Schmidt var. mandshuricum (Maxim.) Kitag. and Asarum sieboldii Miq. from Asarum maximum Hemsl. and Asarum sieboldii Miq. var. seoulense Nakai. The details are provided in Table 1.

After obtaining the results of paired-end sequencing, we use the de novo function in the CLC Genomics Work bench to splice the paired-end sequencing. The paired-end reads were merged with Geneious v8.0.4. For the consistence sequence, ITSx v1.1 is used to cut out the ITS2 sequence and modify the degenerate base (when there are low-quality sequence and high-quality sequence nucleotides in the same site, we prefer high-quality sequence nucleotides) [27]. The sequence alignment, which is given in the Supplementary Materials (available here), was obtained by aligning the sequences of different products using MAFFT v7 [28].

The sequence alignment was compared with the GenBank database, which used the Basic Local Alignment Search Tool (BLAST) to determine the species contained in each sample [29]. The results indicated that the Asarum herbs were derived from four species including Asarum heterotropoides Fr. Schmidt var. mandshuricum (Maxim.) Kitag., Asarum sieboldii Miq., Asarum sieboldii Miq. Var. seoulense Nakai, and Asarum maximum Hemsl (Table 2). We also used the sequence alignment to construct the neighbor-joining (NJ) phylogenetic tree by NJ tools with MEGA-X molecular evolutionary genetic analysis software (see Figure 2). The results demonstrated that Asarum samples from four species formed a stable branch. The type of compounds were similar in closely related species. The branches of Asarum sieboldii Miq. were dispersed, which was probably related to the number of samples. By comparative analysis of the ITS2 sequence, we found that numerous transformation/transversion and insertion/deletion phenomena had occurred in the ITS2 sequence, and the information loci were abundant, which could be used for molecular identification of these samples.

The linear calibration curves of peak areas $(y)$ versus concentrations $(x)$ were plotted for the 10 volatile compounds. The regression coefficients $\left(r^{2}\right)$ were $>0.994$ for the 10 compounds, indicating good linearity within a relatively wide range of concentrations. For precision, the relative standard deviations (RSD) for the contents of the 10 characteristic components ranged from 1.8 to $6.1 \%$. In a test of repeatability, the RSD values for all target analytes ranged from 2.3 to $8.9 \%$. The results indicated that the method is precise and repeatable. Stability, measured as RSD, was in the range $2.2-6.6 \%$, indicating that the samples were stable for $24 \mathrm{~h}$. The recovery of each analyte ranged from 89.2 to $113.3 \%$. These results indicated that the efficiency of sample preparation was acceptable. The full-scan monitoring chromatograms of the analytes are shown in Figure 3. The validation data shown in Table 3 are considered to be satisfactory for the subsequent analysis of all samples.

The validated method was applied to the analysis of 16 batches of raw and processed Asarum samples. Ten bioactive compounds of Asarum were quantified using the external standard method based on their respective calibration curves. The contents of the 10 compounds in raw and 


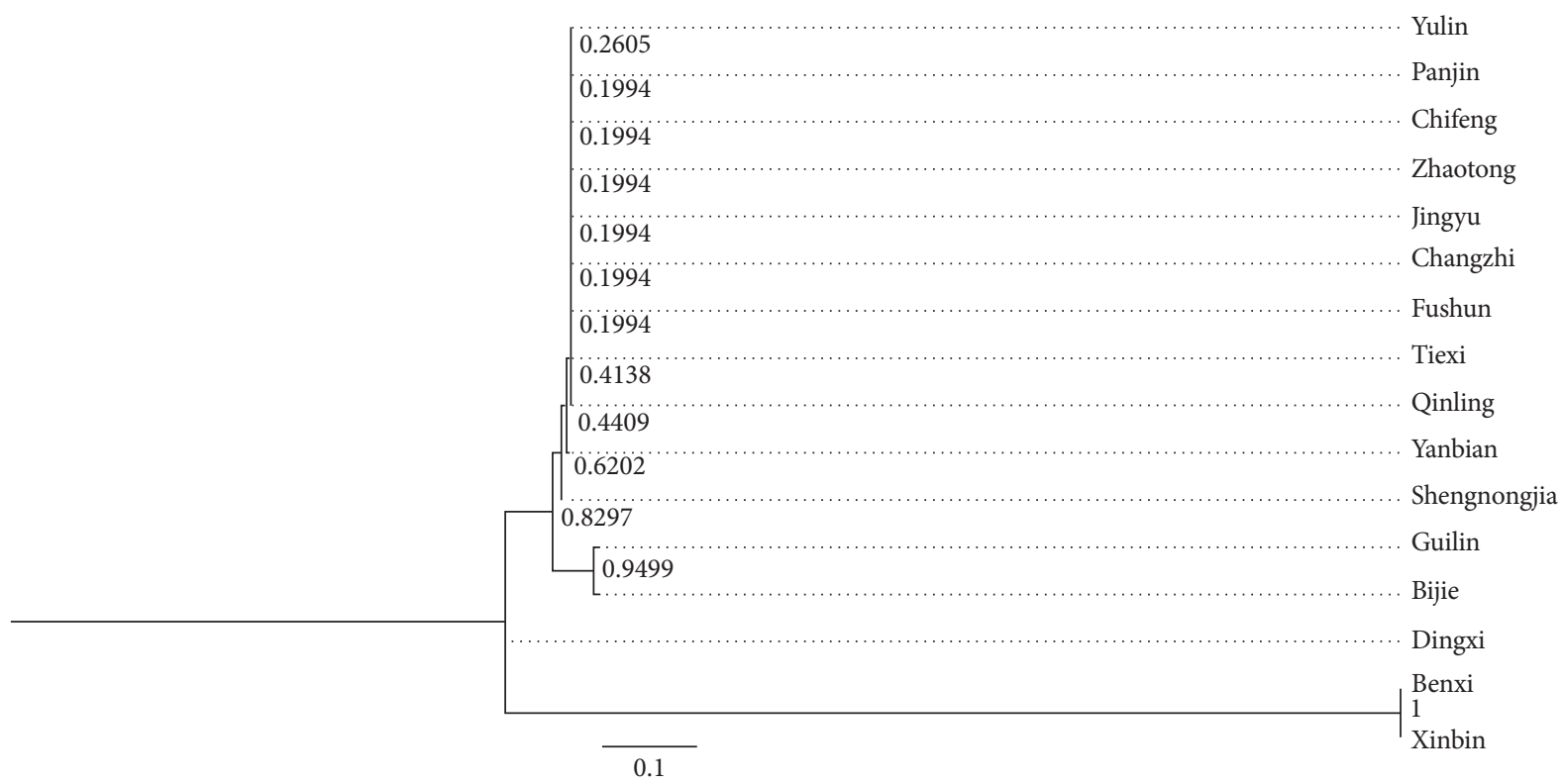

Figure 2: Neighbor-joining (NJ) phylogenetic trees of different Asarum species based on ITS2 sequences.

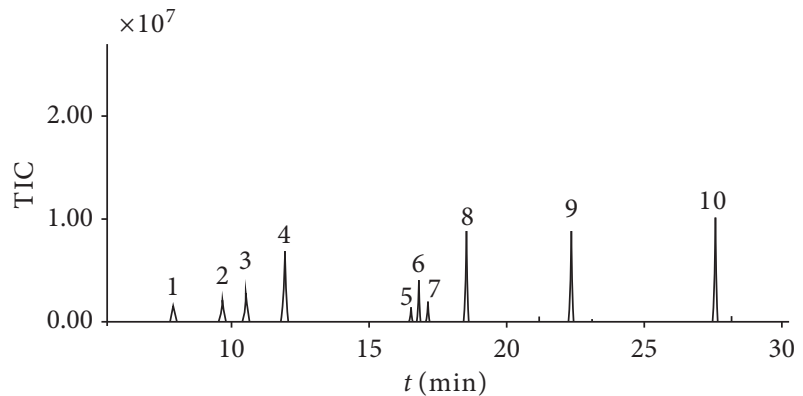

(a)

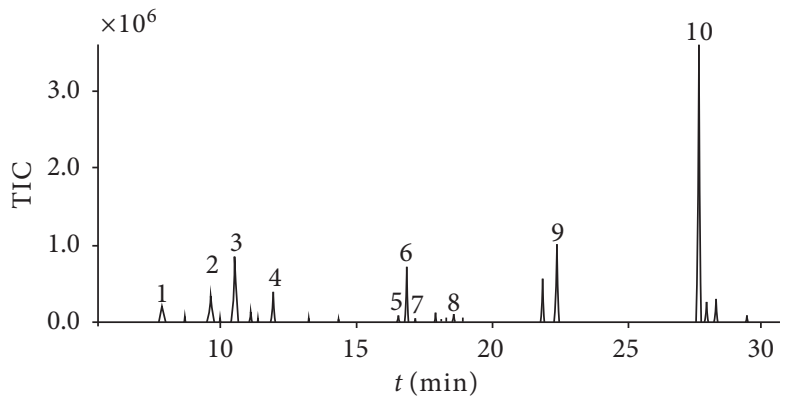

(b)

Figure 3: Full-scan monitoring chromatograms of (1R)-(+)-alpha-pinene (1), (-)- $\beta$-pinene (2), (+)-car-3-ene (3), cineole (4), (-)-borneol (5), 2,6,6-trimethylcyclohepta-2,4-dien-1-one (6), $\alpha$-terpineol (7), estragole (8), safrole (9), and methyleugenol (10): (a) standard solution; (b) Asarum sample.

TABLE 3: Regression equation, linear range, correlation coefficients $\left(r^{2}\right)$, LLOQ, precision, repeatability, stability, and recovery of 10 investigated analytes $(n=6)$.

\begin{tabular}{|c|c|c|c|c|c|c|c|c|}
\hline Compounds & Regression equation & $\begin{array}{c}\text { Linear range } \\
(\mu \mathrm{g} / \mathrm{mL})\end{array}$ & $r^{2}$ & $\begin{array}{c}\text { LLOQ } \\
(\mu \mathrm{g} / \mathrm{mL})\end{array}$ & $\begin{array}{l}\text { Precision } \\
\text { RSD (\%) }\end{array}$ & $\begin{array}{c}\text { Repeatability } \\
\text { RSD (\%) }\end{array}$ & $\begin{array}{l}\text { Stability } \\
\text { RSD (\%) }\end{array}$ & $\begin{array}{c}\text { Recovery } \\
(\%)\end{array}$ \\
\hline (1R)-(+)-alpha-Pinene & $y=110696.5 x-19785.11$ & $0.08-64$ & 0.999 & 0.03 & 3.4 & 4.5 & 2.2 & 94.8 \\
\hline$(-)-\beta$-Pinene & $y=103513.6 x-18753.84$ & $0.1-80$ & 0.999 & 0.05 & 4.0 & 4.9 & 2.7 & 105.7 \\
\hline (+)-Car-3-ene & $y=81430.83 x+6001.557$ & $0.1-80$ & 0.999 & 0.02 & 4.2 & 4.4 & 2.5 & 102.6 \\
\hline Cineole & $y=31324.58 x+51269.66$ & $0.25-200$ & 0.998 & 0.03 & 4.3 & 8.9 & 4.1 & 95.5 \\
\hline $\begin{array}{l}(-) \text {-Borneol } \\
2,6,6-\end{array}$ & $y=99069.16 x-5912.898$ & $0.1-80$ & 0.999 & 0.02 & 3.4 & 6.1 & 2.6 & 108.1 \\
\hline $\begin{array}{l}\text { Trimethylcyclohepta- } \\
\text { 2,4-dien-1-one }\end{array}$ & $y=51336.33 x+33969.81$ & $0.12-96$ & 0.999 & 0.02 & 6.1 & 4.5 & 5.4 & 94.5 \\
\hline$\alpha$-Terpineol & $y=61057.91 x-10884.64$ & $0.05-40$ & 0.999 & 0.04 & 6.0 & 8.8 & 6.6 & 89.2 \\
\hline Estragole & $y=49990.04 x+171669.0$ & $0.3-240$ & 0.996 & 0.01 & 1.8 & 6.5 & 5.5 & 102.3 \\
\hline Safrole & $y=35569.62 x+225493.1$ & $0.6-480$ & 0.997 & 0.02 & 4.0 & 5.5 & 3.6 & 111.3 \\
\hline Methyleugenol & $y=51970.14 x+466412.8$ & $0.6-480$ & 0.994 & 0.01 & 5.1 & 2.3 & 5.1 & 101.2 \\
\hline
\end{tabular}




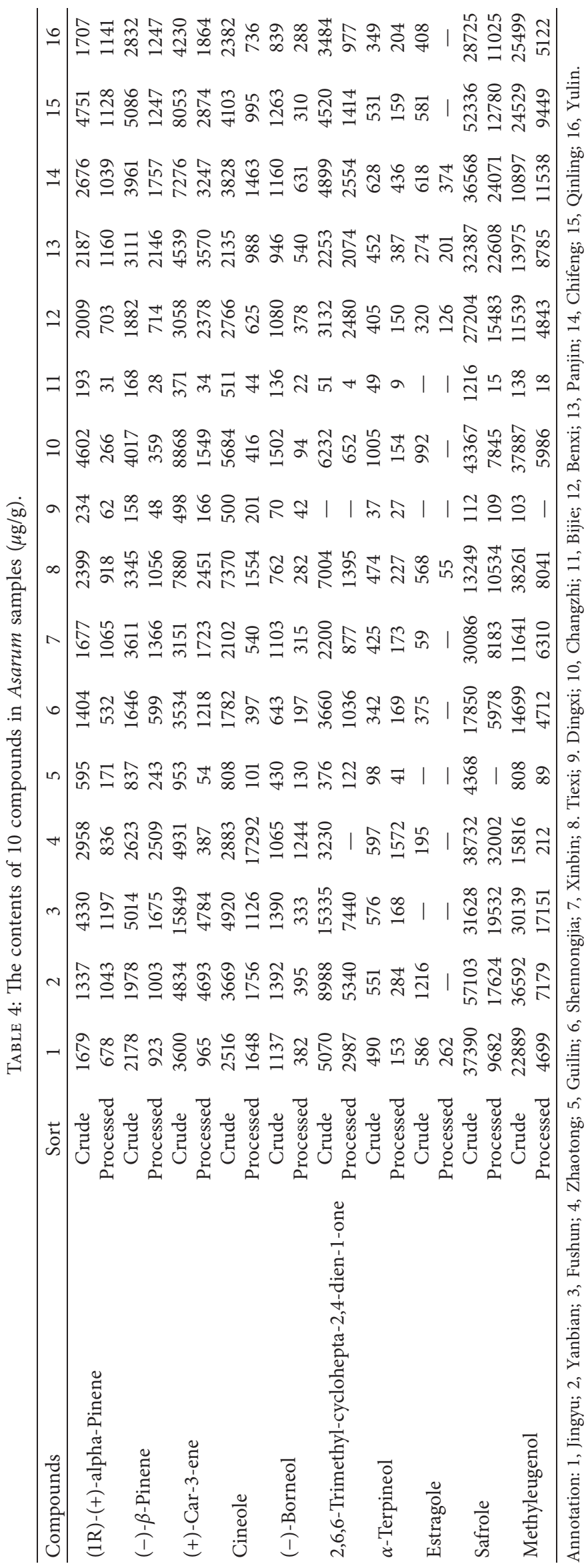




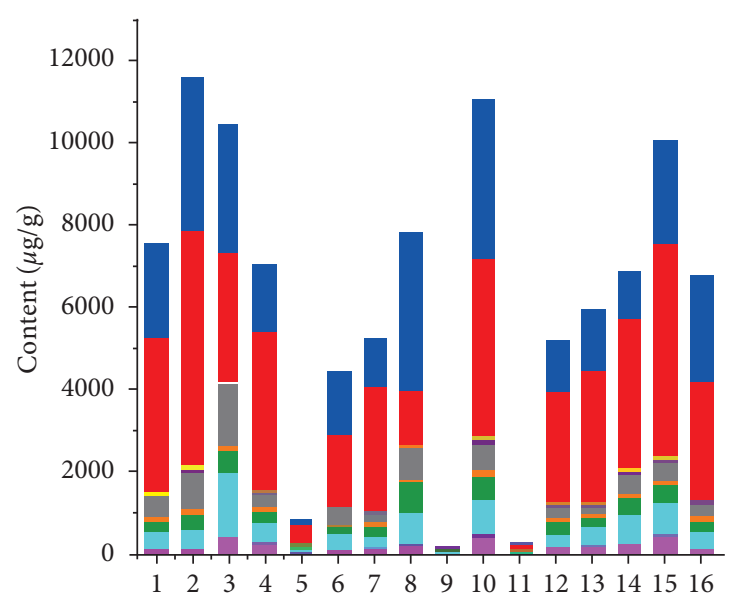

(a)

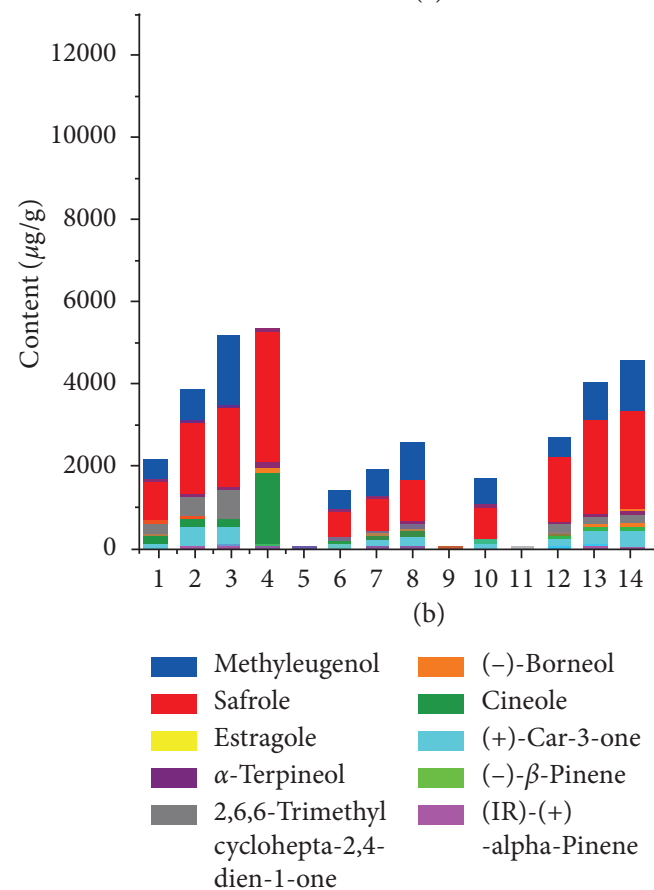

Figure 4: The total contents of 10 volatile components in different batches of raw (a) and processed (b) Asarum samples ( $\mu \mathrm{g} / \mathrm{g})(1$, Jingyu; 2 , Yanbian; 3, Fushun; 4, Zhaotong; 5, Guilin; 6, Shennongjia; 7, Xinbin; 8, Tiexi; 9, Dingxi; 10, Changzhi; 11, Bijie; 12, Benxi; 13, Panjin; 14, Chifeng; 15, Qinling; 16, Yulin).

processed Asarum samples are listed in Table 4. There were differences in the contents of analytes between raw and processed samples. As illustrated in Figure 4, there were obvious differences in the total contents of 10 components. For example, the total contents of 10 ingredients in processed Asarum were significantly decreased when compared with raw Asarum.

Most samples were clearly clustered into distinct groups corresponding to their species types (see Figure 5). The samples of Asarum heterotropoides Fr. Schmidt var. mandshuricum (Maxim.) Kitag. and Asarum sieboldii Miq. were relatively scattered but Asarum maximum Hemsl. samples were more closely clustered together. Compared with Asarum maximum Hemsl., Asarum sieboldii Miq. and Asarum sieboldii Miq. var. seoulense Nakai were located closer to Asarum heterotropoides Fr. Schmidt var. mandshuricum (Maxim.) Kitag. The corresponding score plot combined with VIP values screened out compounds, namely, safrole and methyleugenol for the differentiation of the various Asarum samples. The important variables were selected using the criteria that VIP $>1$ (see Figure 6). The result of the PLS-DA demonstrated that variations in content differences could be due to different species being present in the Asarum samples.

The GC-MS results were further analyzed by PLS-DA. A three-dimensional (3D) score plot of the PLS-DA was carried out to measure the differences between raw and processed Asarum (see Figure 7). Raw Asarum samples clustered in a relatively discrete larger region, which was distinct from that of the processed samples. The processed samples were in a small region, which indicates that the processed samples are more stable than those of 


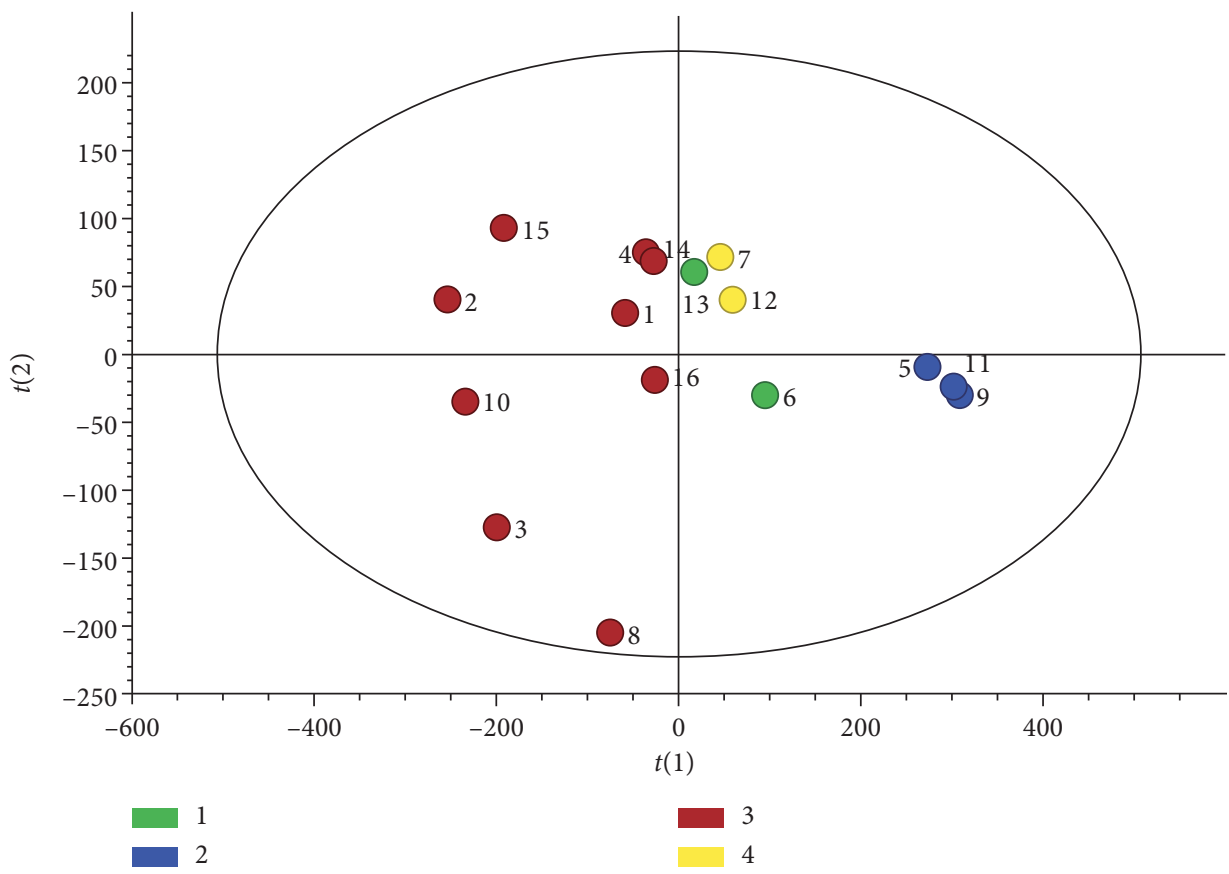

Figure 5: PLS-DA score scatter plot for samples collected from different species: (1) Asarum sieboldii Miq.; (2) Asarum maximum Hemsl.; (3) Asarum heterotropoides Fr. Schmidt var. mandshuricum (Maxim.) Kitag.; and (4) Asarum sieboldii Miq. var. seoulense Nakai $\left(R^{2} X=0.895, R^{2} Y=0.361, Q^{2}=0.246\right)(1$, Jingyu; 2, Yanbian; 3, Fushun; 4, Zhaotong; 5, Guilin; 6, Shennongjia; 7, Xinbin; 8, Tiexi; 9, Dingxi; 10, Changzhi; 11, Bijie; 12, Benxi; 13, Panjin; 14, Chifeng; 15, Qinling; 16, Yulin).

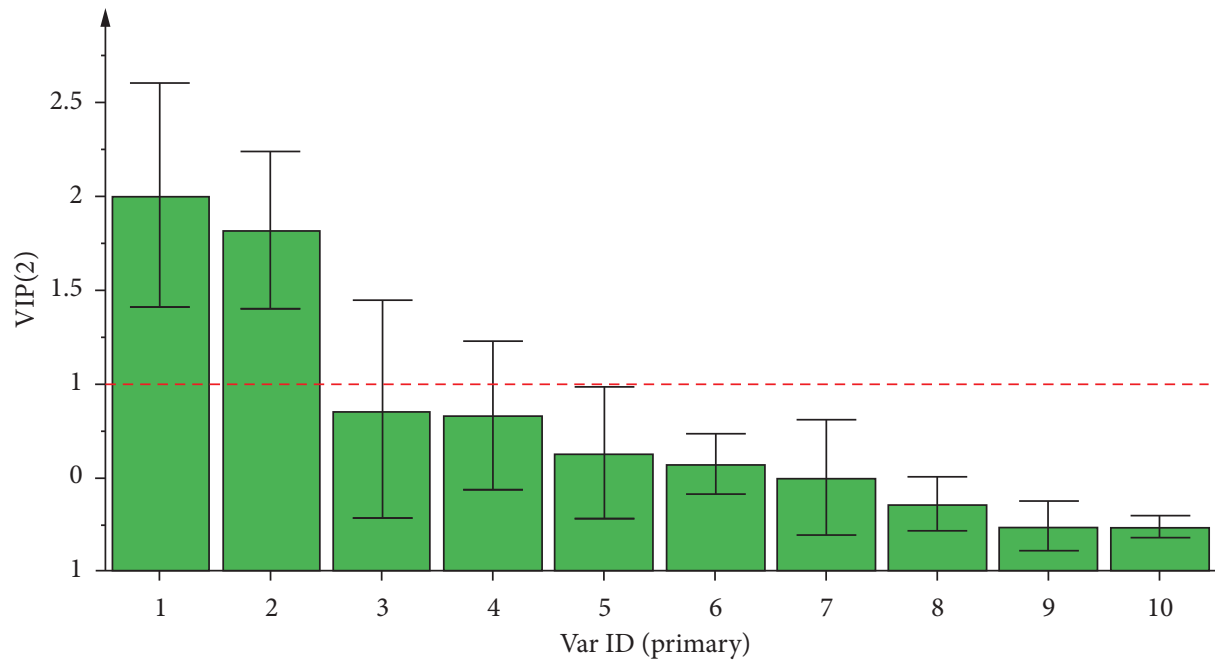

Figure 6: VIP score plot for PLS-DA of Asarum samples collected from different species: (1) safrole; (2) methyleugenol; (3) (+)-car-3-ene; (4) 2,6,6-trimethylcyclohepta-2,4-dien-1-one; (5) cineole; (6) (-)- $\beta$-pinene; (7) (1R)-(+)-alpha-pinene; (8) (-)-borneol; (9) $\alpha$-terpineol; and (10) estragole.

the raw samples. Constituents with large loading values can be considered as markers, which contributed clearly to the classification of the samples. In the present study, potential bioactive ingredients such as safrole, methyleugenol, and 2,6,6-trimethylcyclohepta-2,4-dien-1-one with VIP $>1$ were identified as compounds that could be used to differentiate between the raw and processed Asarum samples (see Figure 8). The results showed that the chemical composition of Asarum samples was altered after processing. The above components contributed greatly to sample classification and may be the material basis for the change of clinical efficacy associated with herb processing.

\section{Conclusions}

In this study, we carried out the character and microscopic identification of Asarum from different species. Microscopic 


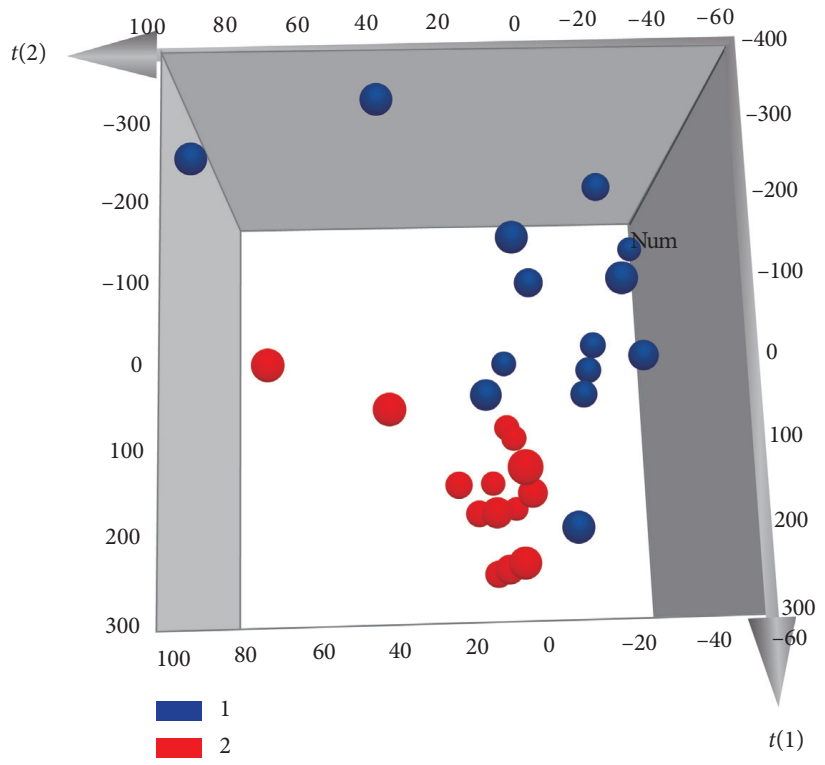

Figure 7: PLS-DA 3D score scatter plot for raw (1) and processed (2) Asarum $\left(R^{2} X=0.861, R^{2} Y=0.44, Q^{2}=0.344\right)$.

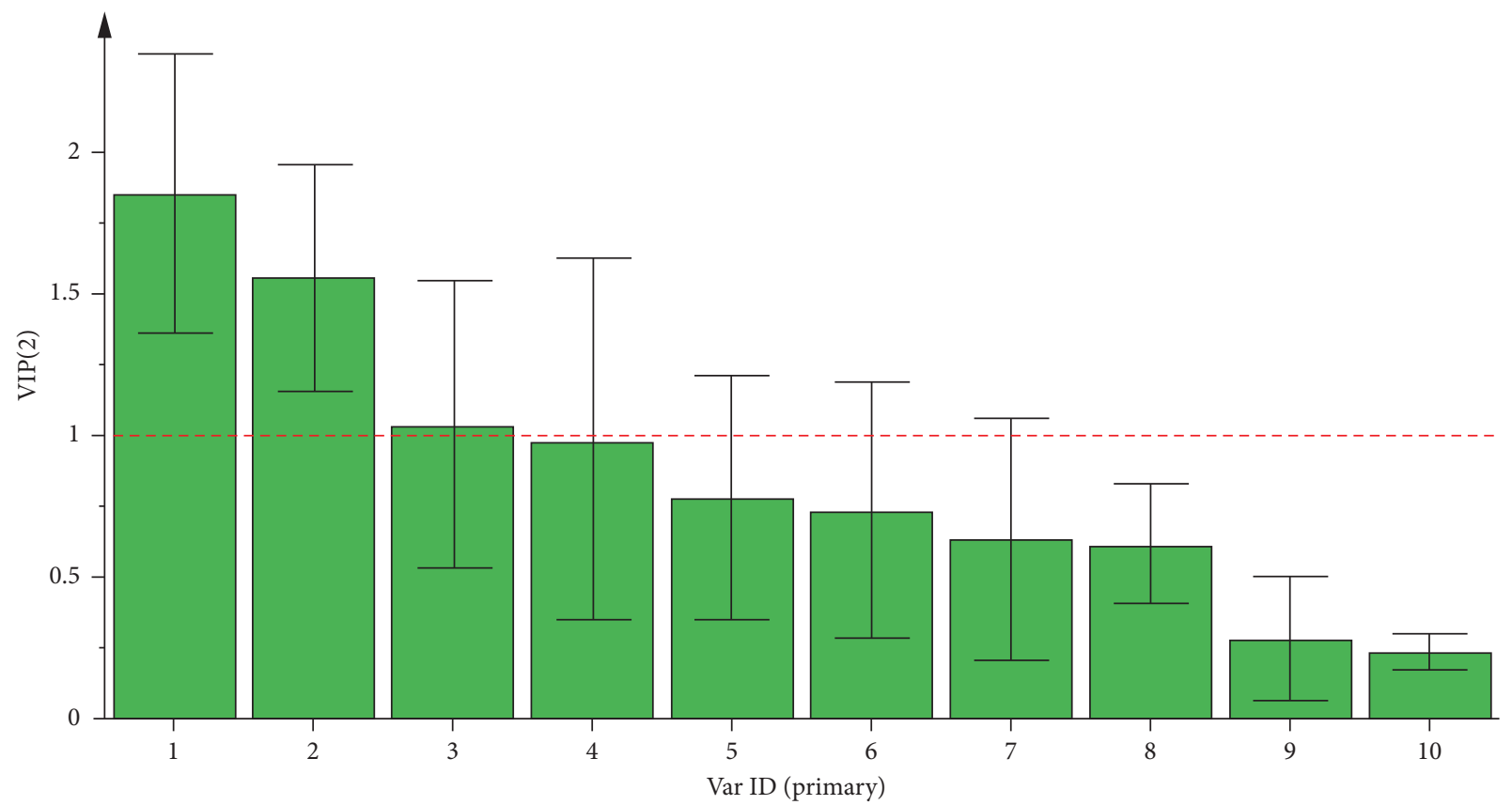

FIGURE 8: VIP score plot for PLS-DA of raw and processed Asarum samples: (1) safrole; (2) methyl eugenol; (3) 2,6,6-trimethylcyclohepta2,4-dien-1-one; (4) cineole; (5) (+)-car-3-ene; (6) (-)- $\beta$-pinene; (7) (-)-borneol; (8) (1R)-(+)-alpha-pinene; (9) estragole; and (10) $\alpha$-terpineol.

observations of Asarum powder samples indicated that a variety of features appeared in different kinds of Asarum samples. As there were many identical cell structures across all samples, a single differential feature could not distinguish the different species apart. Molecular identification technology was then used to identify the above samples, and four species of Asarum were clearly identified from the 16 batches of Asarum samples. Such molecular identification technology makes up for the deficiency of character and microscopic identification.
In addition, a GC-MS method was developed and validated for the simultaneous determination of 10 active components in Asarum samples, and the contents of 16 batches of Asarum samples were investigated by this method, which confirmed the results of the molecular identification. In light of the quantification data of 10 active constituents, PLS-DA analysis was carried out to discriminate and predict Asarum samples of different species and processing methods. Results indicated that raw Asarum samples from different sources in 16 regions could be clearly 
classified into four subclusters by PLS-DA, which verified the results of molecular identification. Two volatile oils (safrole and methyleugenol) with a VIP $>1$ were identified, based on PLS-DA, as key compounds that can be helpful to distinguish the different species apart. Furthermore, the PLS-DA model showed that raw and processed Asarum were clustered in two different areas, respectively. Safrole, methyleugenol, and 2,6,6-trimethylcyclohepta-2,4-dien-1one were significant index constituents to differentiate Asarum samples of different processing methods. The above methods, combining microscopic identification, DNA barcoding, and GC-MS, were established for the identification of raw Asarum and its processed products, which provided the basis for the quality evaluation and species differences of Asarum.

\section{Data Availability}

The data used to support the findings of this study are available from the corresponding author upon request.

\section{Conflicts of Interest}

The authors declare that there are no conflicts of interest regarding the publication of this paper.

\section{Acknowledgments}

This study was supported by the National Natural Science Foundation of China (81673824) and National Major Science and Technology Major Projects of China (2018ZX01031301).

\section{Supplementary Materials}

Alignment sequences of Asarum from 16 regions. (Supplementary Materials)

\section{References}

[1] Pharmacopoeia Commission of People Republic of China, Pharmacopoeia of the People's Republic of China, China Medical Science Press, Beijing, China, 1st edition, 2015.

[2] Z. L. Yang, "The Geographical distribution of Asarum (Aristolochiaceae) from Sichuan province in China," Guihaia, vol. 8, no. 1, pp. 83-88, 1988.

[3] Z. L. Xu, J. G. Pan, Q. C. Zhu et al., "Analysis of volatile oil from Asarum in China by GC-MS (The third reports)," Bulletin of Chinese Materia Medica, vol. 11, no. 1, pp. 46-49, 1986.

[4] B. B. Wang, W. Qi, L. L. Wang et al., "Comparative study of chemical composition, antinociceptive effect and acute toxicity of the essential oils of three Asarum drugs," Journal of Chinese Pharmaceutical Sciences, vol. 23, no. 7, pp. 480-489, 2014.

[5] J. Huang, H.-Q. Wang, C. Zhang, G.-Y. Li, R.-C. Lin, and J.-H. Wang, "A new tetrahydrofuran-type lignan with antiinflammatory activity fromAsarum heterotropoidesFr. Schmidt var.mandshuricum," Journal of Asian Natural Products Research, vol. 16, no. 4, pp. 387-392, 2014.

[6] Y. G. Xu, C. Cao, M. Y. Shang et al., "Assessment on antinociception and anti-inflammation pharmacodynamics of
Asarum heterotropoides var mandshuricum and Asarum sieboldii," China Journal of Chinese Materia Medica, vol. 37, no. 5, pp. 625-631, 2012.

[7] A. S. M. T. Haque, J. N. Moon, P. S. Saravana, A. Tilahun, and B.-S. Chun, "Composition of Asarum heterotropoides var. mandshuricum radix oil from different extraction methods and activities against human body odor-producing bacteria," Journal of Food and Drug Analysis, vol. 24, no. 4, pp. 813-821, 2016.

[8] H. L. Cao, G. F. Cao, J. H. Wei et al., "Effects of genetical and environmental factors on medicinal plant quality," Chinese Traditional and Herbal Drugs, vol. 38, no. 5, pp. 785-788, 2007.

[9] Y. Jing, Y.-F. Zhang, M.-Y. Shang et al., "Phenanthrene derivatives from roots and rhizomes of Asarum heterotropoides var. mandshuricum," Fitoterapia, vol. 117, pp. 101-108, 2017.

[10] B. P. Pimple, A. N. Patel, P. V. Kadam, and M. J. Patil, "Microscopic evaluation and physicochemical analysis of Origanum majorana Linn leaves," Asian Pacific Journal of Tropical Disease, vol. 2, pp. S897-S903, 2012.

[11] D. Kumar, A. Kumar, and O. Prakash, "Morphoanatomical and physicochemical standardization of Casuarina equisetifolia L. stem bark," Beni-Suef University Journal of Basic and Applied Sciences, vol. 3, no. 1, pp. 32-36, 2014.

[12] P. Mishra, A. Kumar, A. Nagireddy et al., "DNA barcoding: an efficient tool to overcome authentication challenges in the herbal market," Plant Biotechnology Journal, vol. 14, no. 1, pp. 8-21, 2015.

[13] R. Lahaye, M. van der Bank, D. Bogarin et al., "DNA barcoding the floras of biodiversity hotspots," Proceedings of the National Academy of Sciences, vol. 105, no. 8, pp. 2923-2928, 2008.

[14] M. Zagorec, M. Champomier-Vergès, and C. Cailliez-Grimal, "Identification methods-identification methods and DNA fingerprinting: whole genome sequencing," Encyclopedia of Food Microbiology, vol. 2, pp. 295-299, 2014.

[15] S. L. Chen, B. L. Guo, G. J. Zhang et al., "Advances of studies on new technology and method for identifying traditional Chinese medicinal materials," China Journal of Chinese Materia Medica, vol. 37, no. 8, pp. 1043-1055, 2012.

[16] S. Zhao, T. Y. Xin, W. Y. Hou et al., "Identification of codonopsis Radix and its adulterants using the ITS/ITS2 barcodes," World Science and Technology-Modernization of Traditional Chinese Medicine, vol. 15, no. 3, pp. 421-428, 2013.

[17] F. Wang, B. Wang, L. Wang et al., "Discovery of discriminatory quality control markers for Chinese herbal medicines and related processed products by combination of chromatographic analysis and chemometrics methods: radix Scutellariae as a case study," Journal of Pharmaceutical and Biomedical Analysis, vol. 138, pp. 70-79, 2017.

[18] X. Zhou, L. Tang, H. Wu et al., "Chemometric analyses for the characterization of raw and processed seeds of Descurainia sophia (L.) based on HPLC fingerprints," Journal of Pharmaceutical and Biomedical Analysis, vol. 111, p. 6, 2015.

[19] X. Wu, X. Chen, Q. Huang, D. Fang, G. Li, and G. Zhang, "Toxicity of raw and processed roots of Polygonum multiflorum," Fitoterapia, vol. 83, no. 3, pp. 469-475, 2012.

[20] B. C. Cai, K. M. Qin, H. Wu et al., "Chemical mechanism during Chinese medicine processing," Progress in Chemistry, vol. 24, no. 4, pp. 637-649, 2013.

[21] X. W. Zhang, J. Huang, D. M. Song et al., "Determination of primary components in Asarum heterotropoides var mandshuricum by different years and different drying methods," Modern Chinese Medicine, vol. 20, no. 9, pp. 1110-1113, 2018. 
[22] M. Jiang, D. Wu, R. R. Li et al., "Cloning and sequence analysis of rDNA ITS from plants in genus Asarum L," Chinese Traditional and Herbal Drugs, vol. 48, no. 14, pp. 2937-2942, 2017.

[23] C. S. Liu, G. B. Bai, and Y. N. Yan, "Studies on the botanical sources and DNA molecular identification of Herba Asari based on ITS sequence," China Journal of Chinese Materia Medica, vol. 30, no. 5, pp. 329-332, 2005.

[24] L. M. Kelly, "Phylogenetic relationships in Asarum (Aristolochiaceae) based on morphology and ITS sequences," American Journal of Botany, vol. 85, no. 10, pp. 1454-1467, 1998.

[25] T. Daiki and S. Hiroaki, "Molecular phylogeny and taxonomic implications of Asarum (Aristolochiaceae) based on ITS and matK sequences," Plant Species Biology, vol. 33, no. 1, pp. 28-41, 2017.

[26] Y. Dan, H.-Y. Liu, W.-W. Gao, and S.-L. Chen, "Activities of essential oils from Asarum heterotropoides var. mandshuricum against five phytopathogens," Crop Protection, vol. 29, no. 3, pp. 295-299, 2010.

[27] J. Bengtsson-Palme, M. Ryberg, M. Hartmann et al., "Improved software detection and extraction of ITS1 and ITS2 from ribosomal ITS sequences of fungi and other eukaryotes for analysis of environmental sequencing data," Methods in Ecology and Evolution, vol. 4, no. 10, pp. 914-919, 2013.

[28] K. Katoh and D. M. Standley, "MAFFT multiple sequence alignment software version 7: improvements in performance and usability," Molecular Biology and Evolution, vol. 30, no. 4, pp. 772-780, 2013.

[29] S. F. Altschul, W. Gish, W. Miller, E. W. Myers, and D. J. Lipman, "Basic local alignment search tool," Journal of Molecular Biology, vol. 215, no. 3, pp. 403-410, 1990. 